\title{
Structural, thermal and enzymatic analysis of naturally occurring and D-amino acid substituted peptides
}

\author{
Punitha Velmurugan, Raghava Rao Jonnalagadda*, Balachandran Unni Nair \\ Council of Scientific and Industrial Research-Central Leather Research Institute, Chemical Laboratory, Chennai, India \\ Email: *jrrao@clri.res.in
}

Received 6 August 2012; revised 8 September 2012; accepted 15 October 2012

\begin{abstract}
Designing of new peptide materials for biomedical and protein engineering applications are important. In the present work an attempt has been made to study the effect of D-Leu in collagen like tetra peptide on the structure and stability of peptide against enzymes and results are compared with its chiral counterpart L-form. Effect of replacement of L-Leu in Leu-Gly-Pro-Ala tetra peptide with D-Leu on structure has been studied using circular dichroic spectroscopy (CD). Our findings suggest that, D-Leu substitution leads to conformational changes in LeuGly-Pro-Ala secondary structure from $\beta$-sheet to turns. $\mathrm{L} \rightarrow$ D-Leu Configurational changes in Leu-GlyPro-Ala owes to enhanced thermal stability which has been substantiated through $C D$ and differential scanning calorimetry. Change in chirality of the leucine inhibits collagenolytic activity, which enables to design selective inhibition of proteases with greater specificity.
\end{abstract}

Keywords: Collagen-Like Peptide; Configurational Change; Leu-Gly-Pro-Ala; Collagen; Chirality; Amino Acid

\section{INTRODUCTION}

Chirality plays a central role in all forms of life. One of life's most distinctive biochemical signatures is its strong selectivity for chiral molecular species, notably L-amino acids (L-AAs) and D-sugars. Polypeptides can adopt many secondary structural conformations in which amino acid sequence and its chirality direct the folding of the polypeptide chain to a defined conformation. Amino acids (AAs) are one of the most essential molecules in living organisms. Most natural proteins are comprised of 19 L-AAs and glycine, which is achiral. Despite this, there are studies that show the presence of D-AAs in the tissues of higher organisms, including human beings [1].

"Corresponding author.
For example, D-Serine (D-Ser) plays an important role in neuroplasticity, memory [2,3] and learning, D-aspartic acid (D-Asp) is involved in endocrine functions [4]. D-AAs are associated with neurotransmission, hormonal synthesis in mammals and protection from proteolysis in bacteria [5]. In case of mammals, D-AAs appear as products of the vital activities of endogenous flora or during spontaneous racemization of AAs in ageing. Accumulation of D-AAs in proteins changes the tertiary and quaternary structures of the proteins. Hence, functional activity has been altered. D-AAs are observed in organs and tissues in various diseases, mainly in acute and chronic diseases of the nervous system, including amyotropic sclerosis, parkinson's disease, Alzheimer's disease, and Huntington's chorea, etc. [6].

Although D-AAs possess both pros and cons in the in-vivo in natural proteins, it has conformational attributes that are useful for the imposition of conformational stability and as structural probes in finding the pathway of the protein folding [7]. D-AAs are increasingly becoming an important building block in the production of pharmaceuticals and chemicals such as chiral directing auxiliaries, and chiral synthons in organic synthesis [810]. The use of D-AAs (unbound or as a component of proteins) may also provide new therapeutic possibilities because they have specific and highly effective in action. Some groups of enzymes perform stereo-specific functions by recognition of enantiomers of chiral substrates. The mechanism of actions of some drugs is based on the fact that different enantiomers of the drug have opposite effects. Arnold et al., demonstrates that incorporation of non-natural amino acids in proteins accelerates folding and enhances its conformational stability [11]. Raleigh and coworkers elucidate Gly is suitable for D-AA substitution, particularly in several globular proteins, which greatly enhances the conformational stability [12]. In addition to that, according to Valiyaveetil and Xie coworkers, replacement of Gly with L- and D-AA, comparatively D-AA substitutions holding the protein function without perturbing protein structure $[13,14]$.

Studies on the incorporation of D-AA in the collagen-like polypeptide sequences are limited. Collagen 
consists of three polypeptide chains $(\alpha)$ with the characteristic triplet sequence Gly- $\mathrm{X}_{\mathrm{AA}}-\mathrm{Y}_{\mathrm{AA}}$, where $\mathrm{G}$ is glycine and $\mathrm{X}_{\mathrm{AA}}$ and $\mathrm{Y}_{\mathrm{AA}}$ can be any L-AA. The three polypeptide chains adopt a polyproline II conformation due to the presence of imino acids in the $\mathrm{X}_{\mathrm{AA}}$ and $\mathrm{Y}_{\mathrm{AA}}$ positions. Hitherto, Bella and Beck coworker establishes the substitution of Gly by L-Ala greatly destabilizes the triple helix and leads to human diseases $[15,16]$. On the other hand, Raines and coworkers suggest that, replacement of Gly residue with D-ala and D-Ser residues lead to the formation of triple helical conformation [17]. Substitution of D-Asp instead of Pro in Acetyl-(Gly-ProHyp) ${ }_{8}$-Gly-Gly-amide sequence leads to destabilization, but mixture of L and D-Asp in Gly-Pro-Hyp sequence comparatively stabilizes the triple helical conformation [18]. In our earlier studies, host-guest peptide approach combined with MD simulation has been utilized to explore the effect of D-amino acids (Asp, Ala and Pro) on the structure and stability of collagen. Results reveal that, D-AA substitution in the collagen like peptides tends to form kink at the substituted site. Interestingly, D-AA substitution doesn't unwind the triple helix, comparatively; D-Ala substituted triple-helical model results in more stable conformation when compared to that of D-Pro and D-Asp [19]. In nature, L $\rightarrow$ D-AA configurational change has been observed in collagen on exposure to UV radiation, high-temperature conditions and ageing. The rate of conversion of chirality is an intrinsic property of each amino acid. Typically, rapid racemization has been found for aspartic acid, followed by alanine $\approx$ glutamic acid $>$ leucine $\approx$ isoleucine $[1,18]$. As mentioned earlier, D-AAs in polypeptide sequence are resistive to proteolytic activity. Can $\mathrm{L} \rightarrow \mathrm{D}$ Configurational change in the cleavage site of the bacterial collagenase in collagen like peptide have an effect on proteolysis, conformation, and thermal stability? To this correspondence, we have studied using N-(3-[2-Furyl]acryloyl)-(L-Leu)-Gly-ProAla and N-(3-[2-Furyl]acryloyl)-(D-Leu)-Gly-Pro-Ala strands because Leu-Gly bond is susceptible to proteolysis.

\section{MATERIALS AND METHODS}

N-(3-[2-Furyl]acryloyl)-(L-Leu)-Gly-(L-Pro)-(L-Ala) (FA-(L-Leu)-Gly-Pro-Ala) and collagenase type 1A were procured from Sigma Chemicals Co., USA.

N-(3-[2-Furyl]acryloyl)-(D-Leu)-Gly-(L-Pro)-(L-Ala) (FA-(D-Leu)-Gly-Pro-Ala) peptide was custom-built by Sigma Chemicals Co., USA. All other reagents used were of analytical grade for the study and sourced from SRL Ltd., India.

\subsection{Secondary Structural Analysis-CD Spectroscopy}

Dichroic spectroscopy measurements were conducted on a JASCO J-815 CD spectrophotometer equipped with a Peltier thermoelectric temperature control-423S/15 (JASCO Inc.). Peptide solutions of concentrations $0.5 \mathrm{mg} / \mathrm{mL}$ were used, in $10 \mathrm{mM}$ Tris buffer, $\mathrm{pH}$ 7.4, were equilibrated at $4^{\circ} \mathrm{C}$ for more than $48 \mathrm{~h}$ prior to analysis. For $\mathrm{CD}$ data collection, $350 \mu \mathrm{l}$ of each peptide was used in a $0.1 \mathrm{~cm}$ path length quartz cuvette. Wavelength was scanned between 190 to $350 \mathrm{~nm}$, using $1.0 \mathrm{~nm}$ bandwidth, $0.1 \mathrm{~nm}$ step size, and an averaged time of $1 \mathrm{~s}$. The raw data in millidegree units were corrected for background absorbance and converted to molar ellipticity $[\theta]$. Dichroic signature of the peptide has been analyzed with the seconddary Structural Estimation Application in JASCO's Spectra Manager software to obtain the fraction of helix, beta sheet, turn, and random coil secondary structure using Yang's and Reed's references.

\subsection{Thermal Stability-CD Spectroscopy}

Thermal analysis was carried out by recording CD spectra with increase in temperature. For wavelength scans, the signal was collected from 190 to $350 \mathrm{~nm}$ at $1 \mathrm{~nm}$ intervals, at $20^{\circ} \mathrm{C}$ to $60^{\circ} \mathrm{C}$ by increasing temperature in $1{ }^{\circ} \mathrm{C} / \mathrm{min}$. For equilibrium melting temperature $\left(\mathrm{T}_{\mathrm{m}}\right)$ transitions, the ellipticity at 202 and $192 \mathrm{~nm}$ was monitored while the sample temperature was increased from $20^{\circ} \mathrm{C}$ to $60^{\circ} \mathrm{C}$ at intervals of $0.5^{\circ} \mathrm{C}$ for FA-(L-Leu)-Gly-Pro-Ala and FA-(D-Leu)-Gly-Pro-Ala, respectively. The equilibration time at each temperature was $10 \mathrm{~s}$, and data were collected at each point. Temperature induced secondary structural changes were determined using Yang's and Reed's references [20,21].

\subsection{Thermal Stability-Differential Scanning Calorimetry}

The temperature dependence of partial heat capacity was analysed via the use of a differential scanning calorimetry (Q200 DSC with refrigerated cooling system 90, TA instruments, Waters). The instrument is equipped with reference and sample cells in which of approximate volume of samples was weighed $(25 \mu \mathrm{L}$ of $2 \mathrm{mg} / \mathrm{mL})$ in sample cell and sealed in a Tzero pan with Tzero hermatic lid. The contents were heated from 20 to $60^{\circ} \mathrm{C}$ at a heating rate of $1^{\circ} \mathrm{C} / \mathrm{min}$. DSC generates data for heat capacity $\left(\mathrm{C}_{\mathrm{p}}\right)$ as a function of temperature. The calorimetric enthalpy $\Delta \mathrm{H}_{\text {cal }}$ was calculated from the area under the curve of the concentration-normalized DSC endotherm.

\subsection{Enzymatic Analysis-UV-Vis Spectroscopy}

Peptide solutions of concentrations $1 \mathrm{mg} / \mathrm{mL}$ in appropriate amount of tricine buffer $(0.05 \mathrm{M}$ tricine, $0.4 \mathrm{M}$ $\mathrm{NaCl}$ and $10 \mathrm{mM} \mathrm{CaCl}_{2}, \mathrm{pH} 7.4$ ) was equilibrated at $4{ }^{\circ} \mathrm{C}$ for more than $48 \mathrm{~h}$ prior to analysis. Peptide samples of 
concentrations $0.5 \mathrm{mg} / \mathrm{mL}$ and Clostridium histolyticum collagenase $(100 \mu \mathrm{L}$ of $1 \mathrm{mg} / \mathrm{mL})$ was added, and the final volume was adjusted to $1 \mathrm{~mL}$. The course of hydrolysis of FA-(L-Leu)-Gly-Pro-Ala and

FA-(D-Leu)-Gly-Pro-Ala were monitored using Perkin Elmer UV-Vis spectrophotometer equipped with a Peltier thermoelectric temperature by following decrease in absorbance at $345 \mathrm{~nm}$ at $37^{\circ} \mathrm{C}$ as a function of time. Peptide without enzyme was used as control and tricine buffer was used as a blank.

\section{RESULTS AND DISCUSSION}

Approach towards selective inhibition of specific proteases is associated with aberrant physiology, and disease emerges as a promising therapeutic strategy. Low specificity of the existing inhibitors explains the lack of success and induces high level of side effects during clinical trials. Consequently, there has been significant interest in using alternative strategies to develop inhibitors with greater specificity. Recently, collagenase inhibitors have been designed as mimics of the cleavage sites of collagenase substrate, which occupies and blocks the active site of the enzymes. One such approach to achieve this has been to target the enzyme-substrate interactions at specific domains of the substrates with configurational changes in the amino acid sequence. The effect of Damino acids on protein stability is of great interest, which leads to study the $\mathrm{L} \rightarrow \mathrm{D}$ configurational changes on Leu-Gly-Pro-Ala collagen like peptide fragment. The reason for choosing LGPA peptide sequence is its wellstudied and more susceptible sequence for bacterial collagenase.

\subsection{Circular Dichroism Studies of the L-Leu $\rightarrow$ D-Leu Mutant Conformational Stability}

A circular dichroic spectrum of L- and D-peptides is shown in Figure 1. CD spectra were recorded for peptides at physiological $\mathrm{pH}$ and temperature at $4^{\circ} \mathrm{C}$ to confirm their unfolded characteristics. LGPA spectra has a negative minimum around $202 \mathrm{~nm}$ and a negative shoulder around $231 \mathrm{~nm}$ with a positive maximum at $303 \mathrm{~nm}$. On the other hand, FA-(D-Leu)-Gly-Pro-Ala shows a negative minimum at $192 \mathrm{~nm}$ and negative shoulder at 209.6 and $303 \mathrm{~nm}$ and a positive maximum at $233.4 \mathrm{~nm}$. The fluoro probe peak which is attached to Leu in the $\mathrm{N}$-terminal is reversed as negative and positive for Land D-enantiomer at $303 \mathrm{~nm}$. Wavelength at 202 and 192 $\mathrm{nm}$ is responsible for the overall peptide folding, i.e. average mean residue molar ellipticity of L- and D-peptides, respectively. $\pi \rightarrow \pi^{*}$ transition of the peptide bond absorbance shifted towards blue side in the presence of D-Leu of $10 \mathrm{~nm}$. Structural analyses of host and guest peptides are reported in Table 1 using the Reed's and

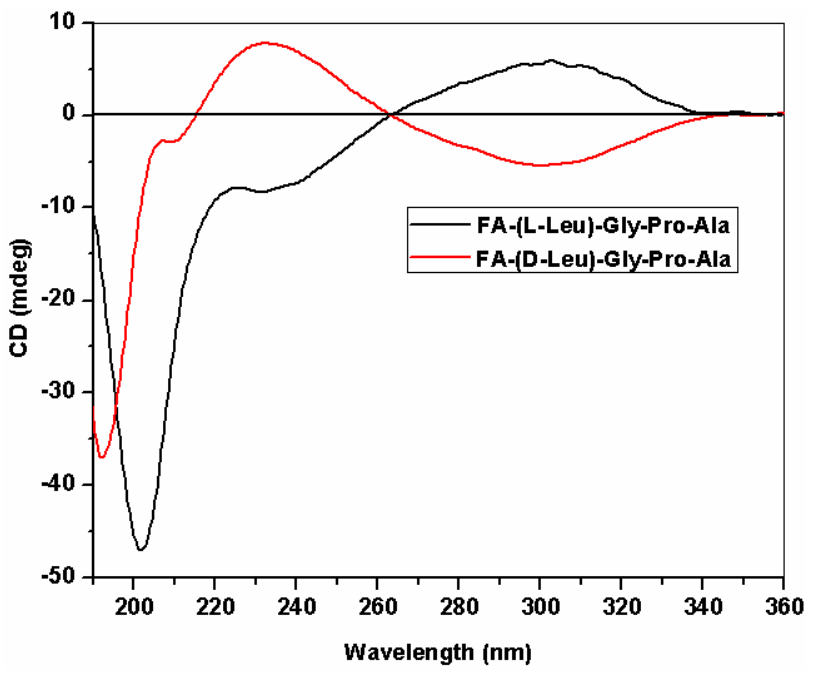

Figure 1. Circular dichroic spectra of $L$ and D peptides.

Table 1. Structural analysis of L- and D-peptides.

\begin{tabular}{ccccc}
\hline \multirow{2}{*}{ Structure } & \multicolumn{2}{c}{ FA(L-Leu)-Gly-Pro-Ala } & \multicolumn{2}{c}{ FA(D-Leu)-Gly-Pro-Ala } \\
\cline { 2 - 5 } & $\begin{array}{c}\text { Yang's } \\
\text { Reference } \\
(\%)\end{array}$ & $\begin{array}{c}\text { Reed's } \\
\text { Reference } \\
(\%)\end{array}$ & $\begin{array}{c}\text { Yang's } \\
\text { Reference } \\
(\%)\end{array}$ & $\begin{array}{c}\text { Reed's } \\
\text { Reference } \\
(\%)\end{array}$ \\
\hline Helix & 0.0 & 7.7 & 0.0 & 0.0 \\
$\beta$ & 43.4 & 25.0 & 16.6 & 0.0 \\
Turn & 7.8 & 2.9 & 42.0 & 24.1 \\
Random & 48.8 & 64.4 & 41.5 & 75.9 \\
\hline
\end{tabular}

Yang's reference set for the secondary structure calculations. Yang's and Reed's reference structural analysis reveals that L- and D-enantiomeric peptides of globular domain cannot adopt helix conformation. According to Yang's reference its predicted that globular domain can support $43.3 \% \beta$-sheet and $48.8 \%$ random coil conformation for FA-(L-Leu)-Gly-Pro-Ala whereas $\beta$-sheet, turn and random coil have been observed for D-enantiomer containing peptide in which turn and random coil conformation are more preferable. In the case of Reed's reference host peptide possess $64.4 \%$ random coil and $25 \% \beta$-sheet conformation, whereas in guest peptide helix and $\beta$-sheet conformation are comparatively disappeared with an increase percentage of turn $(21.2 \%)$ and random coil $(11.5 \%)$ are observed. Guest peptide prefers more random coil conformation when compared to other conformation because tetra peptide doesn't have capacity to form stable secondary structure due to lack of hydrogen bonding.

\subsection{Thermodynamic Analysis via DSC of the L-Leu $\rightarrow$ D-Leu Mutant Peptides}

Studies on thermal stability of peptides were performed using differential scanning calorimetry. DSC measures 
the excess heat capacity of a solution $\left(\mathrm{C}_{\mathrm{p}}\right)$ of the molecule of interest as a function of temperature, shown in
Figure 2. Thermal transitions have been recognized as a sharp endothermic peak centered at $\mathrm{T}_{\mathrm{m}}$. Integration of the

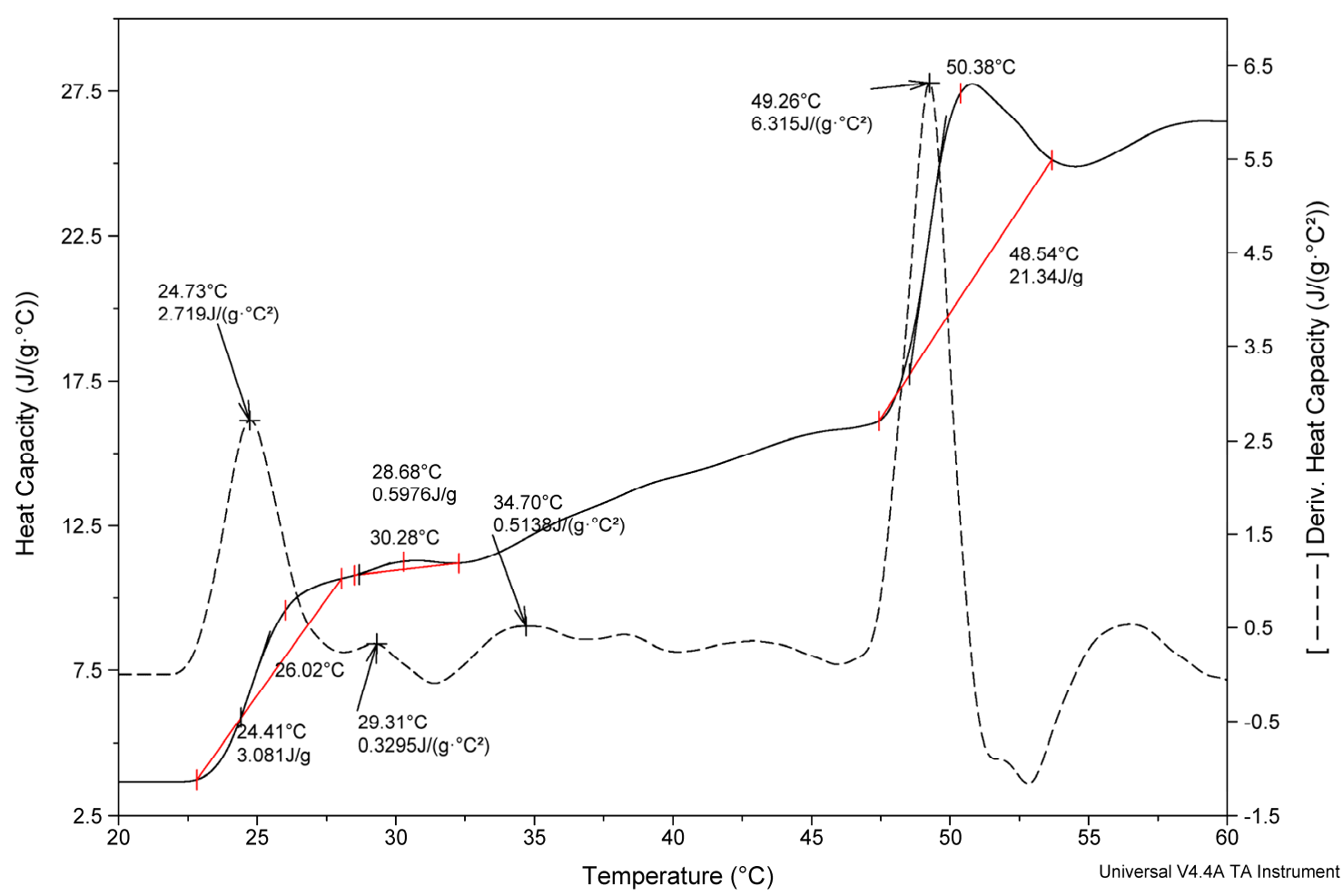

(a)

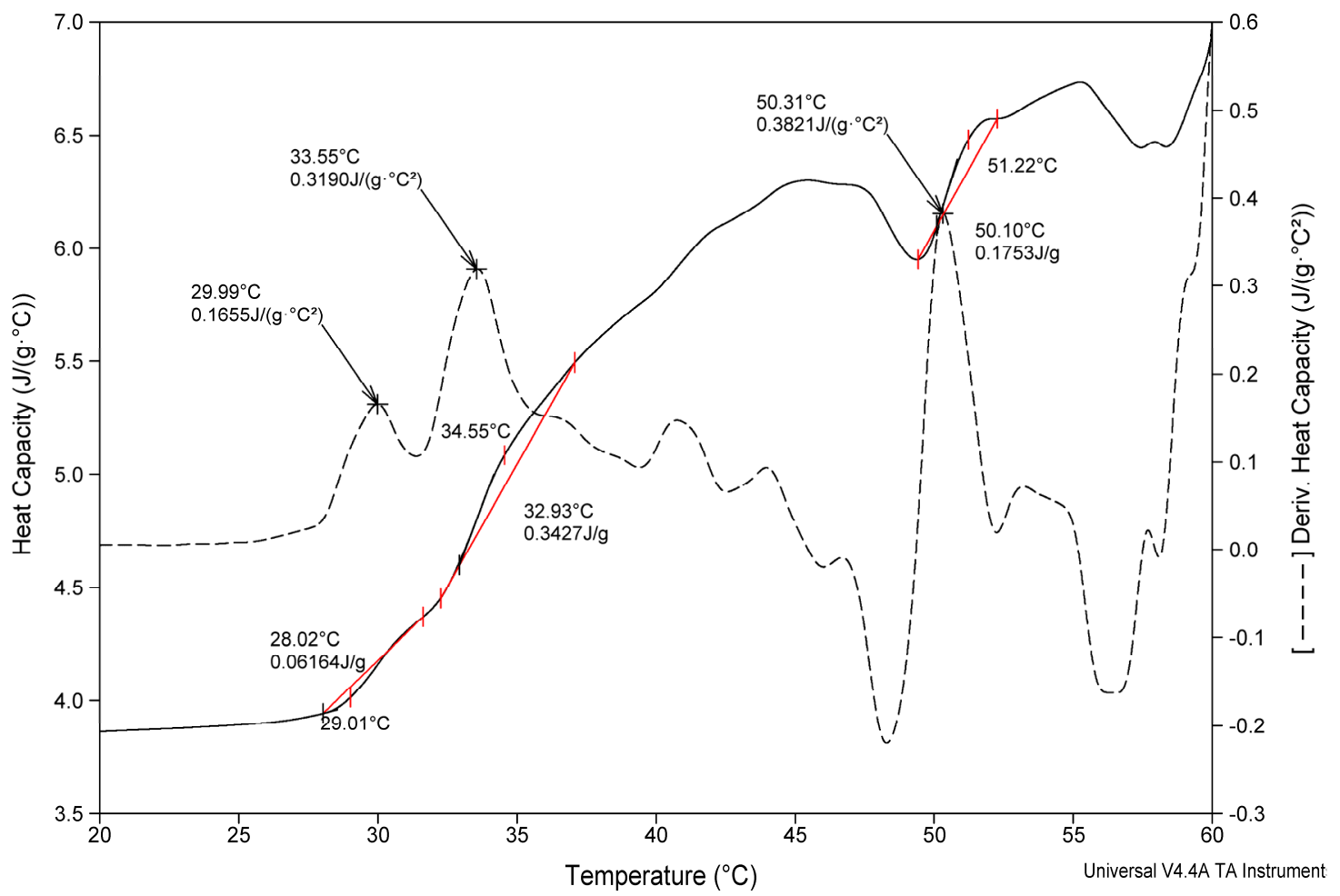

(b)

Figure 2. DSC profile of (a) FA-(L-Leu)-Gly-Pro-Ala and (b) FA-(D-Leu)-Gly-Pro-Ala peptides and its first derivative. 
thermogram $\mathrm{C}_{\mathrm{p}}$ versus $\mathrm{T}$ produces the transition enthalpy $\left(\Delta \mathrm{H}_{\mathrm{m}}^{\circ}\right)$. The value of $\Delta \mathrm{H}_{\mathrm{m}}^{\circ}$, calculated from the area under the transition peak, correlated with the content of ordered secondary structure. Calculated $\Delta \mathrm{H}_{\mathrm{m}}^{\circ}$ value is actually a net value which is a combination of endothermic contribution such as the disruption of hydrogen bonds and exothermic contribution such as the breakup of hydrophobic interactions. The sharpness of the transition peak can be measured as the width at half peak height, and is an index of the nature of transition from native to denatured state. Denaturation of FA-(L-Leu)Gly-Pro-Ala and FA-(D-Leu)-Gly-Pro-Ala do not occur within a narrow temperature range, indicates the kind of transition involved in multistate process. Denatured peptides have a higher heat capacity than native one, so the first transition peak has been considered as denaturation peak. As a result, the $\Delta \mathrm{C}_{\mathrm{p}}$ for unfolding is positive. There are many factors responsible for folding and stability of the peptides, including hydrophobic interaction, hydrogen bonding, and conformational entropy. Moreover $\mathrm{T}_{\mathrm{m}}$ is an indicator of thermal stability, generally the higher the $T_{m}$, the more thermodynamically stable is the peptide. Peptides with higher $T_{m}$ are less susceptible to unfolding and denaturation at lower temperatures. Besides, thermodynamic analysis, reveals that the stability of the FA-(D-Leu)-Gly-Pro-Ala peptide conformation $\left(\mathrm{T}_{\mathrm{m}}=\right.$ $\left.29.99^{\circ} \mathrm{C}\right)$ is higher than that of the FA-(L-Leu)-GlyPro-Ala peptide $\left(\mathrm{T}_{\mathrm{m}}=24.73^{\circ} \mathrm{C}\right)$. A calorimetric study shows that the thermal denaturation of the collagen like small peptide is a complex process, FA-(L-Leu)-GlyPro-Ala consisting of multiple endothermic events, attributing to the thermal unfolding via breaking of hydrogen bonding. In the case of FA-(D-Leu)-Gly-Pro-Ala, DSC profile possesses multiple endo- and exothermic events, attributing to the thermal folding via breakage of hydrogen bonding and hydrophobic interactions. Thermodynamic parameters have been calculated and reported in Table 2. From the table, it is evident that the D-enantiomer substituted peptide gets stabilized entropically, but the enthalpic contribution becomes a destabilizing factor, which leads to increase in $\Delta \mathrm{G}^{\circ}$. In case of natural peptide, conformation is stabilized enthalpically, whereas the entropy contribution becomes a destabilizing factor; this led to increase in overall stability via decrease in $\Delta \mathrm{G}^{\circ}$. However, high concentration $(2 \mathrm{mg} / \mathrm{mL})$ of peptides has been used in DSC measurement leading aggregation of natural and denatured peptides or possibly self-association of native state. This may be the possible reason for multistate transition process.

\subsection{Variable Temperature Circular Dichroic Structural Analysis of Peptides}

The temperature dependent $\mathrm{CD}$ spectroscopic signature of $\mathrm{L}$ and $\mathrm{D}$-enantiomeric peptides has been shown in
Figure 3 with increase in temperature from $20^{\circ} \mathrm{C}$ to $60^{\circ} \mathrm{C}$. This shows a significant drop at a wavelength of $202 \mathrm{~nm}$ for FA-(L-Leu)-Gly-Pro-Ala and 192 and $233 \mathrm{~nm}$ for FA-(D-Leu)-Gly-Pro-Ala peptide. The change in CD ellipticity at 202 and $192 \mathrm{~nm}$ in $\mathrm{pH} 7$ were monitored with increasing temperature for $\mathrm{L}$ and $\mathrm{D}$ peptides, respectively, which provides thermal transition (Figure 4).

Both the peptides showed a broad thermal transition near $20^{\circ} \mathrm{C}$ to $30^{\circ} \mathrm{C}$ with similar melting profile. The non-collagenous globular domain of $\mathrm{L}$ and $\mathrm{D}$ collagen like peptides unfolds at the same time with the slight difference in temperature shows highly cooperative transition under these conditions. The slight stabilizing effect of D-peptide may be due to formation of $\beta$-conformation with increasing temperature. Difference in denaturation temperature which is noticeable among DSC and CD measurements, may be due to the concentration difference; in particular for $\mathrm{CD}$ measurements low concentration $(0.5 \mathrm{mg} / \mathrm{mL})$ of peptides has been used but in the case of DSC higher concentration $(2 \mathrm{mg} / \mathrm{mL})$ has been employed, which leads to aggregation and self-association of native peptides. Peptides exhibited a temperature dependent secondary structural change which has been studied using Yang's and Reed's reference (Figure 5). According to Yang's reference of secondary structural analysis, the host peptide shows a drastic increase in random coil conformation with sudden drop at $20^{\circ} \mathrm{C}$. Further increase in temperature the random coil conformation remains unchanged, with an increase in $\beta$-conformation, decrease in turn and absence of helix. Whereas the Reed's reference of secondary structural analysis reveals, as the temperature increases there is a slight decrease in random coil conformation with increase in $\beta$-sheet conformation, absence of turn and unaltered helix. For guest peptide with increase in temperature it could be made out from the Yang's reference of secondary structural analysis that the random coil conformation decreases slightly with the absence of helix, decrease in turn and increase in $\beta$-sheet conformation. Therefore with Yang's reference it becomes clear that, turns domain is converting into $\beta$-sheet conformation. Whereas the Reed's reference of secondary structural analysis states that with a temperature raise slight increases in the random coil conformation with decrease in turn and absence of helix, infers the conversion turns into random coil conformation.

Table 2. Thermodynamic parameters of FA(L-Leu)-Gly-ProAla and FA(D-Leu)-Gly-Pro-Ala peptides.

\begin{tabular}{lcccc}
\hline Peptide & $\mathrm{T}_{\mathrm{m}}\left({ }^{\circ} \mathrm{C}\right)$ & $\begin{array}{c}\Delta \mathrm{H}_{\mathrm{m}}^{\circ} \\
(\mathrm{kcal} / \mathrm{mol})\end{array}$ & $\begin{array}{c}\Delta \mathrm{S}_{\mathrm{m}}^{\circ} \\
\left(\mathrm{kcal} / \mathrm{mol}^{\circ} \mathrm{C}\right)\end{array}$ & $\begin{array}{c}\Delta \mathrm{G}_{\mathrm{m}}^{\circ} \\
(\mathrm{kcal} / \mathrm{mol})\end{array}$ \\
\hline FA(L-Leu)-Gly-Pro-Ala & 24.73 & 1.3 & 0.358 & -7.65 \\
FA(D-Leu)-Gly-Pro-Ala & 29.99 & 0.003 & 0.004 & -0.11 \\
\hline
\end{tabular}



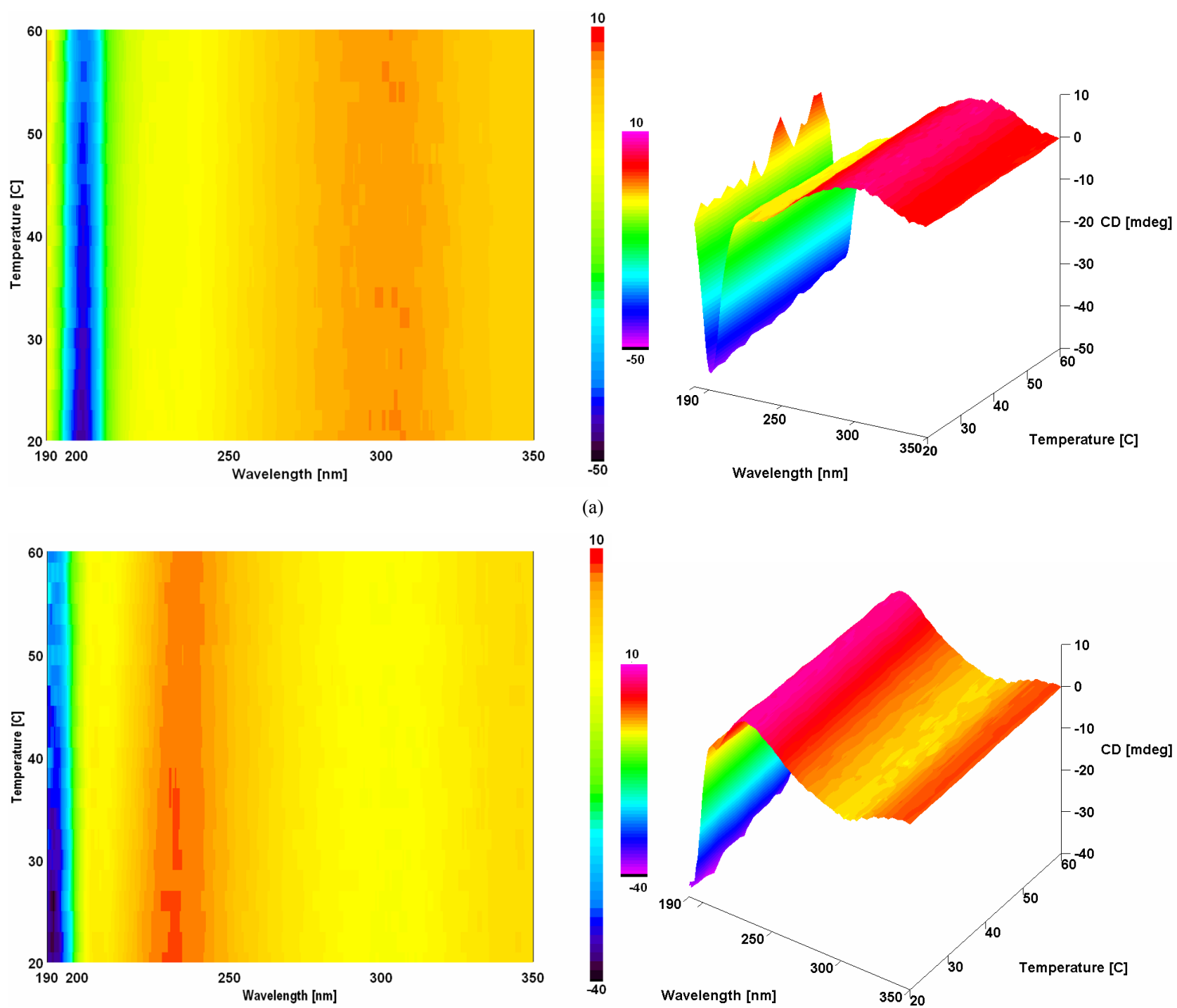

(a)

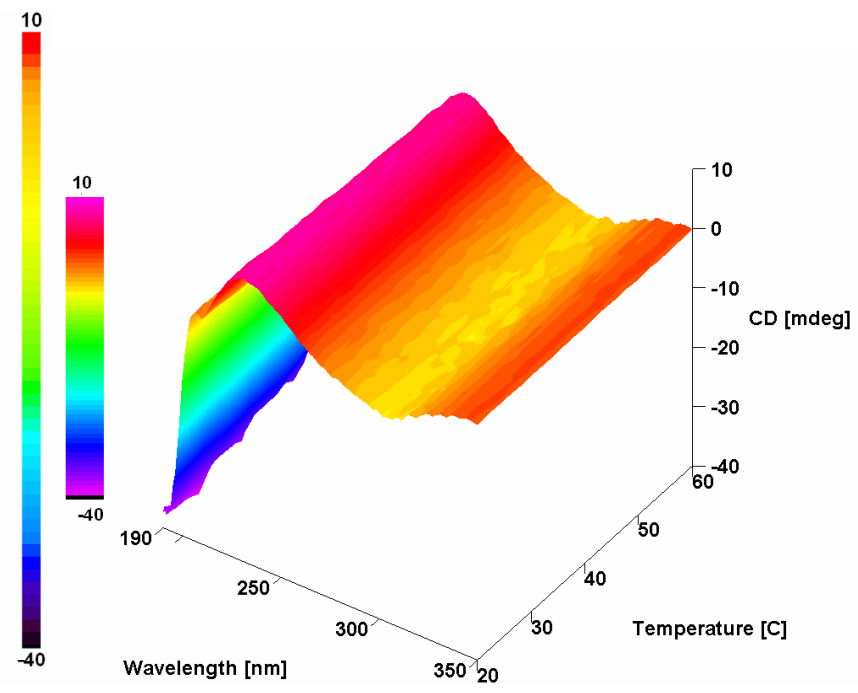

(b)

Figure 3. Temperature interval scan of CD measurements of (a) FA-(L-Leu)-Gly-Pro-Ala and (b) FA-(D-Leu)-Gly-Pro-Ala.

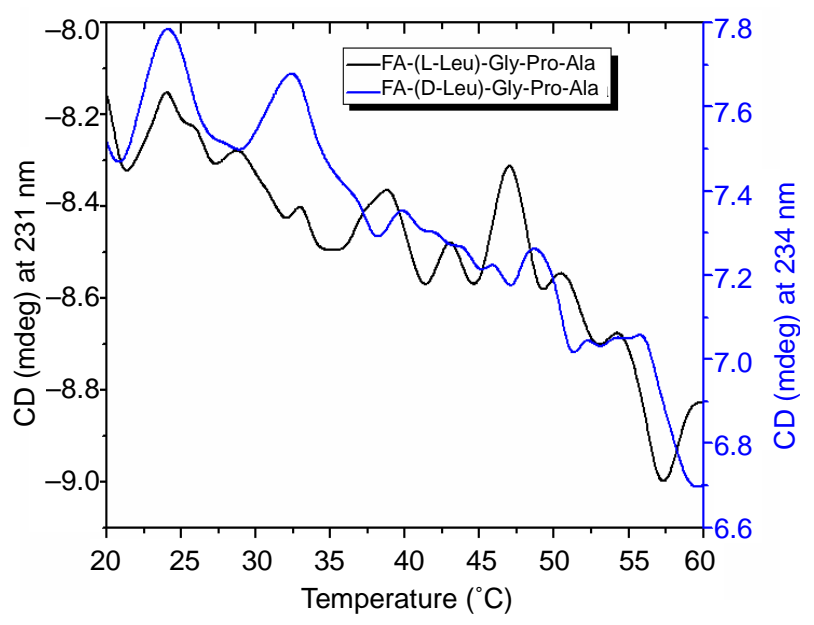

Figure 4. CD measurements on thermal stability of L- and Dpeptides and its first derivative.

\subsection{Enzyme Kinetics}

Collagenolytic behavior has been well examined using triple helical peptide models at collagenase cleavage sites. So far, FA-(L-Leu)-Gly-Pro-Ala has been used to observe the collagenolytic activity of bacterial collagenase. Collagenase activity has been studied using UV-Vis spectroscopy by monitoring the changes in absorbance at $345 \mathrm{~nm}$ as a function of time. FA-(L-Leu)-Gly-Pro-Ala peptide has been recognized by bacterial collagenase, which cleaving Leu-Gly, with the increase in time, which leads to decrease in absorbance of the fluoro probe. Collagenolytic activity of bacterial collagenase on Leu-GlyPro-Ala with change in chirality has been shown in Figure 6. Enzymatic cleavage at (L-Leu)-Gly has been observed on FA-(L-Leu)-Gly-Pro-Ala with increase in time on the other hand on FA-(D-Leu)-Gly-Pro-Ala do not 


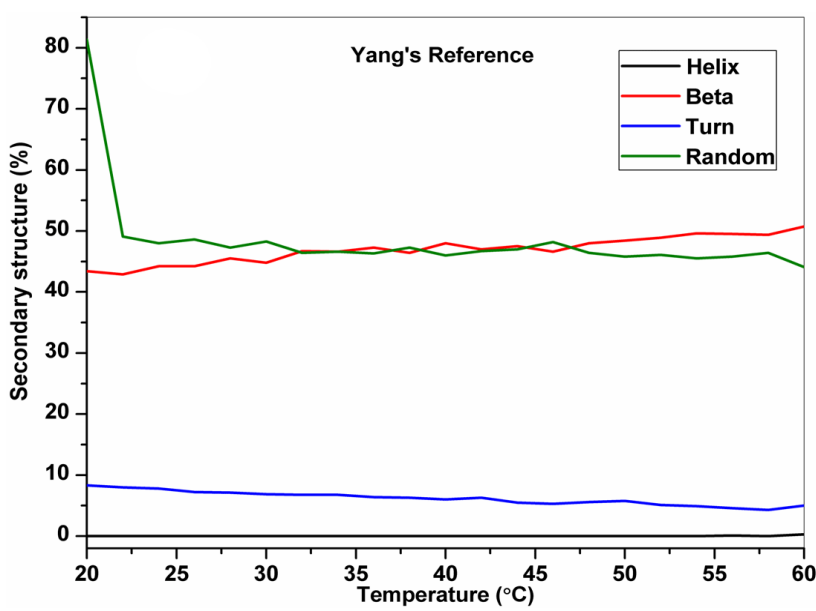

(a)

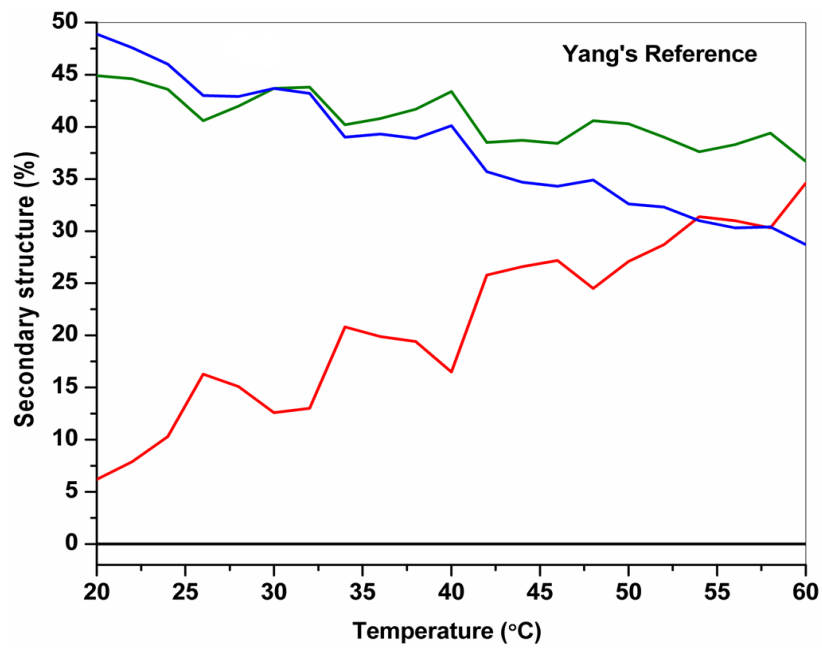

(c)

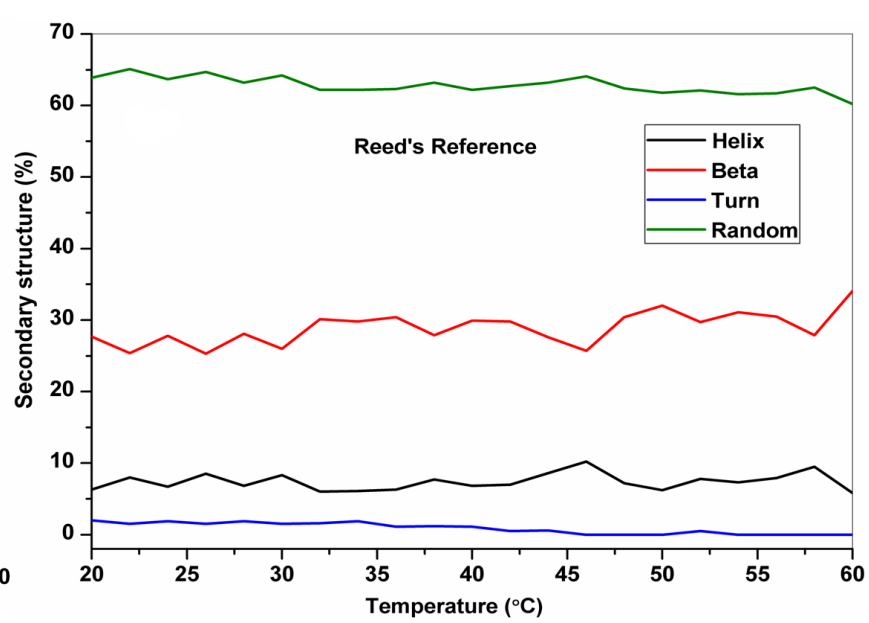

(b)

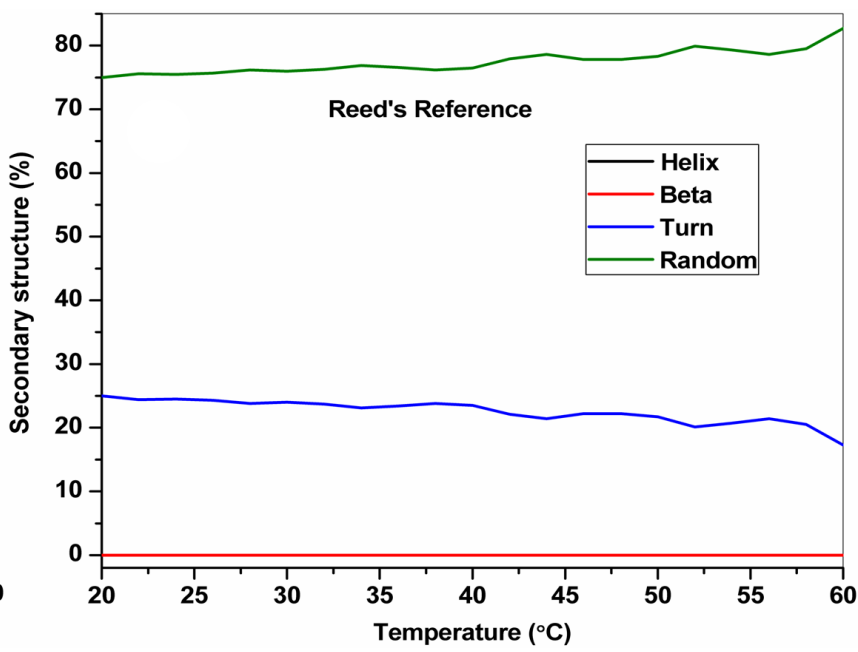

(d)

Figure 5. Changes in the secondary structure of D-Leu substituted peptides with increasing temperature (a) FA-(L-Leu)-Gly-Pro-Ala and (b) FA-(D-Leu)-Gly-Pro-Ala.

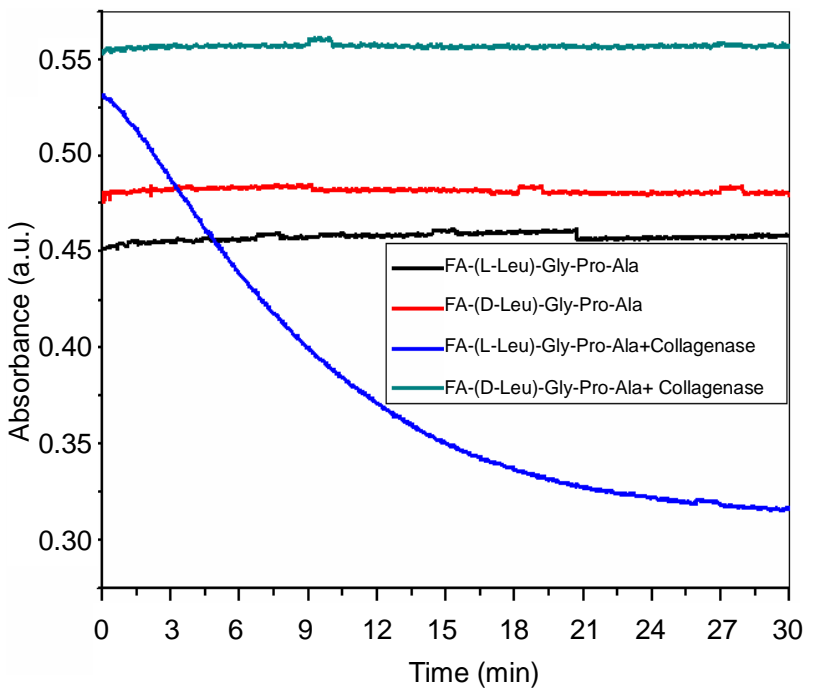

Figure 6. Enzyme kinetics of FA-(L-Leu)-Gly-Pro-Ala and FA-(D-Leu)-Gly-Pro-Ala peptides. show enzymatic activity which substantiates from the spectra because absorbance remains unchanged. Results disclose that $\mathrm{L}$-enantiomeric peptide is recognizable and susceptible for collagenolytic activity but D-Leu substituted peptide is resistant to enzyme degradation. The structure of L- and D-Leu and its corresponding peptides have been shown in Figure 7. Configurational change at the cleavage site of the substrate stabilizes the collagen like peptide against enzymatic hydrolysis.

\section{CONCLUSION}

Present study more precisely shows that collagenase clearly differ in their hydrolyzing abilities on collagen like peptide upon change in chirality of the leucine. DSC reveals increase in thermal stability, which observed on configurational changes in collagen like peptide. D-AA containing peptides can be used as inhibitor because it has the ability to mimic the cleavage site of the colla- 


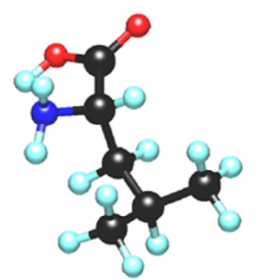

L-Leucine

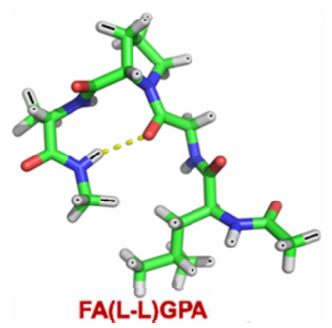

D-Leucine

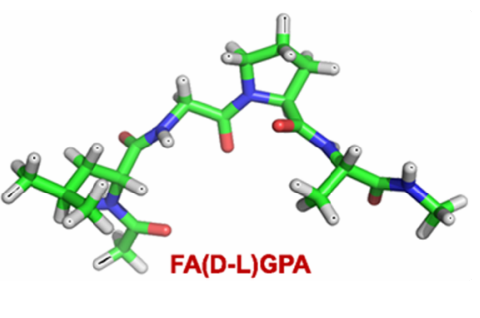

Figure 7. 3-D structures \& models of L-Leu and D-Leu and its corresponding FA-(L-Leu)-Gly-Pro-Ala and FA-(D-Leu)-GlyPro-Ala peptides.

genase and also $\mathrm{L}$ to D-Leu configurational change can be utilized.

\section{ACKNOWLEDGEMENTS}

One of the authors (V.P) wishes to thank the Council of Scientific and Industrial Research, New Delhi, for providing the Senior Research Fellowship.

\section{REFERENCES}

[1] Gineyts, E., Cloos, P.A.C., Borel, O., Grimaud, L., Delmas, P.D. and Garnero, P. (2000) Racemization and isomerization of type I collagen C-telopeptides in human bone and soft tissues: Assessment of tissue turnover. Biochemistry Journal, 345, 481-485. doi:10.1042/0264-6021:3450481

[2] Wolosker, H., Panizzutti, R. and De Miranda, J. (2002) Neurobiology through the looking-glass: D-serine as a new glial-derived transmitter. Neurochemistry International, 41, 327-332. doi:10.1016/S0197-0186(02)00055-4

[3] Wolosker, H. (2007) NMDA receptor regulation by Dserine: New findings and perspectives. Molecular Neurobiology, 36, 152-164. doi:10.1007/s12035-007-0038-6

[4] Kim, P.M., Duan, X., Huang, A.S., Liu, C.Y., Ming, G.L., Song, H. and Snyder, S.H. (2010) Aspartate racemase, generating neuronal D-aspartate, regulates adult neurogenesis. Proceedings of the National Academy of Sciences of the United States of America, 107, 3175-3179. doi:10.1073/pnas.0914706107

[5] Cava, F., Lam, H., de Pedro, M.A. and Waldor, M.K. (2011) Emerging knowledge of regulatory roles of Damino acids in bacteria. Cellular and Molecular Life Sciences, 68, 817-831. doi:10.1007/s00018-010-0571-8

[6] Chervyakov, A.V., Gulyaeva, N.V. and Zakharova, M.N. (2011) D-amino acids in normal ageing and pathogenesis of neurodegenerative diseases. Neurochemical Journal, $\mathbf{5}$, 100-114. doi:10.1134/S1819712411020036

[7] Luo, Z., Zhao, X. and Zhang, S. (2008) Structural dynamic of a self-assembling peptide d-eak16 made of only D-amino acids. PLoS ONE, 3, Article ID: e2364. doi:10.1371/journal.pone.0002364

[8] Vedha-Peters, K., Gunawardana, M., David Rozzell, J. and Novick, S.J. (2006) Creation of a broad-range and highly stereoselective D-amino acid dehydrogenase for the one-step synthesis of D-amino acids. Journal of the American Chemical Society, 128, 10923-10929. doi:10.1021/ja0603960

[9] Merviel, P., Najas, S., Campy, H., Floret, S. and Brasseur, F. (2005) Use of GNRH antagonists in reproductive medicine. Minerva Ginecol, 57, 29-43.

[10] Hauptmann, J. (2002) Pharmacokinetics of an emerging new class of anticoagulant/antithrombotic drugs. A review of small-molecule thrombin inhibitors. European Journal of Clinical Pharmacology, 57, 751-758.

[11] Arnold, U., Hinderaker, M.P., Köditz, J., Golbik, R., UlbrichHofmann, R. and Raines, R.T. (2003) Protein Prosthesis: A nonnatural residue accelerates folding and increases stability. Journal of the American Chemical Society, 125, 7500-7501. doi:10.1021/ja0351239

[12] Anil, B., Song, B., Tang, Y. and Raleigh, D.P. (2004) Exploiting the right side of the Ramachandran plot: Substitution of glycines by D-alanine can significantly increase protein stability. Journal of the American Chemical Society, 26, 13194-13195. doi:10.1021/ja047119i

[13] Valiyaveetil, F.I., Sekedat, M., MacKinnon, R. and Muir, T.W. (2004) Glycine as a D-amino acid surrogate in the $\mathrm{K}^{+}$-selectivity filter. Proceedings of the National Academy of Sciences of the United States of America, 101, 17045-17049. doi:10.1073/pnas.0407820101

[14] Xie, C., Prahl, A., Ericken, B., Wu, Z., Zeng, P., Li, X., Lu, W.Y., Lubkowski, J. and Lu, W. (2005) Reconstruction of the conserved $\beta$-bulge in mammalian defensins using D-amino acids. Journal of Biological Chemistry, 280, 32921-32929. doi:10.1074/jbc.M503084200

[15] Bella, J., Eaton, M., Brodsky, B. and Berman, H.M. (1994) Crystal and molecular structure of a collagen-like peptide at $1.9 \mathrm{~A}^{\circ}$ resolution. Science, $\mathbf{2 6 6}, \mathbf{7 5 - 8 1 .}$ doi:10.1126/science.7695699

[16] Beck, K., Chan, V.C., Shenoy, N., Kirkpatrick, A., Ramshaw, J.A.M. and Brodsky, B. (2000) Destabilization of osteogenesis imperfecta collagen-like model peptides correlates with the identity of the residue replacing glycine. Proceedings of the National Academy of Sciences of the United States of America, 97, 4273-4278. doi:10.1073/pnas.070050097

[17] Horng, J.C., Kotch, F.W. and Raines, R.T. (2007) Is glycine a surrogate for a D-amino acid in the collagen triple helix? Protein Science, 16, 208-215. doi:10.1110/ps.062560107

[18] Shah, N.K., Brodsky, B., Kirkpartrick, A. and Ramshaw, J.A.M. (1999) Structural consequences of D-amino acids in collagen triple-helical peptides. Biopolymers, 49, 297-302. doi:10.1002/(SICI)1097-0282(19990405)49:4<297::AID- 


\section{BIP4>3.0.CO;2-Q}

[19] Punitha, V., Sundar Raman, S., Parthasarathi, R., Subramanian, V., Raghava Rao, J., Nair, B.U. and Ramasami, T. (2009) Molecular dynamics investigations on the effect of D-amino acid substitution in a triple-helix structure and the stability of collagen. Journal of Physical Chemistry B, 113, 8983-8992. doi:10.1021/jp808690m

[20] Chang, C.T., Wu, C.S.C. and Yang, J.T. (1978) Circular dichroism analysis of protein conformation: Inclusion of $\beta$-turns. Analytical Biochemistry, 91, 13-31. doi:10.1016/0003-2697(78)90812-6

[21] Reed, J. and Reed, T.A. (1997) A set of constructed type spectra for the practical estimation of peptide secondary structure from circular dichroism. Analytical Biochemistry, 254, 36-40. doi:10.1006/abio.1997.2355 